\title{
Mathematical Modelling of Aquatic Ecosystem
}

\author{
Sharif E. Guseynov ${ }^{1,2, a}$, Jekaterina V. Aleksejeva ${ }^{1, b}$ \\ ${ }^{1}$ Institute of Mathematical Sciences and Information Technologies, Liepaja University, 14 \\ Liela Street, Liepaja LV-3401, Latvia; ${ }^{2}$ Institute of Aeronautics, Faculty of Transport and \\ Mechanical Engineering, Riga Technical University, 1A Lomonosov Street, Building-1, Riga \\ LV-1019,_Latvia ${ }^{a}$ Sh.E.Guseinov@inbox.lv, J Jekaterina.V.Aleksejeva@gmail.com
}

\begin{abstract}
In present paper we consider the complete statements of initial-boundary problems for the modelling of various aspects of aqueous systems in Latvia. All the proposed models are the evolutionary models: all they are nonstationary and continuous qualitative models having the dynamic parameters and aimed at analysis, evaluation and forecast of aquatic environmental quality (i.e. quality of reservoirs, lakes and seas). In constructing these mathematical models as research tools classic apparatus of differential equations (both ODE and PDE) as well as apparatus of mathematical physics were used.
\end{abstract}

Keywords: Aqueous ecosystem, environmental pollution, mathematical modelling, multicomponent dynamic model.

\section{INTRODUCTION}

Since the second half of the XX century the increasing growth of anthropogenic impact on the environment has led to exacerbation of many ecological problems. Prospects for reducing (full solution is not even discussed) the influence of such ecological problems on human life-sustaining activities are connected with implementation of "sustainable development" concept (see, for instance, [1]-[5] and respective references given in these), the main point of which is to ensure the stable coexistence between mankind and nature, which in its turn requires at least to save and reproduce the resource potential; improving the structure of ecosystem exploitation on the basis of scientific approach and performing an analysis for identifying the objective characteristic of ecological situation in order to take a reasonable (even non-optimal) solution; improving the level of human health. All these necessary conditions for implementation of "sustainable development" concept require: development of models and algorithms for unbiased and adequate evaluation of ecosystems' stability; finding out the relationships for dynamics of environmental problems; improvement of both models and methods of ecological and economic forecasts; studying of the combined effect of the anthropogenic loads influencing the ecosystem at large, etc.

The main toolkit in all these studies is mathematical modelling (see, for instance, [1], [2], [5], [6]-[11]) and / or simulation (see, for instance, [7], [12]-[15]), as well as analytical and numerical methods for solving the constructed models. Among the mathematical models the special place is taken by qualitative models, which are one of the most efficient tools of system analysis - the main approach to the study of ecological systems at various levels. System analysis still remains the only tool, in case if carrying out of large-scale field studies and experiments is encumbered because of technical and economic reasons, or is just impossible.

In the construction of mathematical models (both qualitative and quantitative) it is necessary to take into account existing peculiarities of ecological problems. The reason of the specific character of ecological problems is rooted, firstly, in the utmost uncertainty of problems formulation, and, secondly, in the complexity of problems, when it is required to take into account diverse factors starting from geology factors up to the pollution level of atmospheric air, seas and oceans.

As far as engineering practice is concerned, it is known that the error of quantitative assessments and calculations could be as large as hundreds percent. The results obtained in [6] in the study of two-boxed model for the investigation of metabolic processes in the Baltic Sea clearly show the hypersensitivity of water unit even to insignificant discharge amount of human activity wastes (the results of [3] show a similar hypersensitivity in the Black Sea). Eventually, the goal of using formal methods in environmental design, mathematical modelling and forecasting is a more accurate calculation for the scope of ecological damage, forthcoming financial costs as well as 
effectiveness evaluation for the applied countermeasures.

Latvia is one of the most successful European countries in ecological problems solving. In accordance with the Environmental Performance Index 2014 (see [16]) Latvia takes 40th place among 178 countries in the world by the purity of the environment. The Environmental Performance Index, which produced by a team of environmental experts at the Yale University and the Columbia University, is constructed through the calculation and aggregation of 20 indicators reflecting national-level environmental data. These indicators are combined into nine issue categories (Environmental Health: 1. Health Impacts, 2. Air Quality, 3. Water and Sanitation; Ecosystem Vitality: 4. Water Resources, 5. Agriculture, 6. Forests, 7. Fisheries, 8. Biodiversity and Habitat, 9. Climate and Energy), each of which fit under one of two overarching objectives.

However, Latvia has room for improving the ecological problems. First of all, for improving the problem of Baltic Sea health. Latvia has more than 500 kilometers of beach along the Baltic Sea, which is among the most polluted seas in the world. According to the assessment presented in [17], none of the open basins of the Baltic Sea had an acceptable status. Only a very few coastal areas along the Gulf of Bothnia can be considered healthy. Implementation of special international agreements and cross-border programs as well as various studies and research is the way towards a healthy and sustainably-used Baltic Sea.

The second opportunity of improving the problem of the environment of Latvia concerns air pollution, which is particularly heavy during windless, cloudy weather. The main air pollutants are sulfur dioxide, formaldehyde, phenols, ammonia, and nitrogen oxides. The transport and energy sectors are the main sources of air pollutant emissions in Latvia. On average more than $80 \%$ of atmosphere pollution in Europe cities comes from motor transport as result of gas burn out. The chemical content of exhaust depends on gas type and quality, processing technology, burn out technique inside of motor, its technical condition and following filtration of exhaust (see, for instance, [12], [19] and respective references given in these). Improving air quality is one of the main priorities of Latvia's environmental policy [18]).

\section{MODELS OF AQUATIC ECOSYSTEM}

A. The qualitative model for determination of pollutant concentration dynamics in the "layered in respect to depth" Baltic Sea at a known velocity of pollutant transfer

In this subsection a mathematical model is proposed for determination of pollutant concentration dynamics in the Baltic Sea. For constructing of this model the Baltic Sea was divided into parallel narrow horizontal layers, which are perpendicular to the internal normal in respect to the surface of the sea. Moreover, it was supposed that the velocity of pollutant transfer in each layer is priory known. The given assumption, obviously, is a quite strong requirement that reduces the value of the offered model to some extent, since determination of pollutant transfer velocity for any non-homogenous environment, including the Baltic Sea, is considered to be independent and quite tough problem. However, despite the limiting role of the given assumption, the offered mathematical model can be used as primary model for deeper monitoring of the eco-state of the Baltic Sea. Indeed, if roughly assuming that in each layer for some small period of time the velocity of pollutant transfer is constant (this could be achieved by executing the following procedure: significantly increasing the quantity of divisions into sea layers and at the same time significantly reducing the time for study of the pollutant distribution process), then, by using the offered model, after finding its analytical solution, it is possible to determine the quantity of the transferred pollutant amount in each layer with quite high accuracy. Then there appears a question: what is the limitation of the model if after the abovementioned procedure it becomes possible to determine the dynamics of pollutant concentration with a fairly high degree of accuracy? The answer is simple:

- the ideal accuracy of the solution found is only possible with an infinite increase of the layers number and with an infinite reduction of the time period at which the dynamics of pollutant concentration is investigated;

- sufficient accuracy of the solution found is possible at a very large increase of the layers number and at essential reduction of research time period that demands huge computing resources - on the edge of possibilities of modern supercomputers relevant to the possible maximum volume of RAM, CPU throughput, and maximal number of servers joined into cluster having the outmost parallel computing performance, etc.;

- the model is unstable, i.e. rather quite small changes in initial data can lead to a rather large discrepancy between the solution found and the ideal exact solution, which exists, is unique and unknown and which is intended to be reached. Therefore, it is necessary not just to solve the offered model, but to develop a stable method of its solution, having a regularization (by Tikhonov) property. It should be noted that this issue is relatively easily solved.

So, by denoting as $D$ the studied three dimensional domain of the Baltic Sea, and as $u(x, y, z ; t)$ the desirable concentration of harmful substance in this domain $D$ at the moment of time $t$, the proposed model implies the following: it is necessary to 
determine the function $u(\xi, t)$, where $u(\xi, t),(\xi, t) \in D \times[0, T], D \subset \mathbb{R}^{3}, \quad$ which satisfies the equation

$$
\begin{array}{r}
\frac{\partial u(\xi, t)}{\partial t}=\nabla_{\xi}\left(a(\xi) \cdot \nabla_{\xi} u(\xi, t)\right) \\
+\left\langle\alpha, \nabla_{\xi} u(\xi, t)\right\rangle+\beta \cdot u(\xi, t)+f(\xi, t), \\
\xi \in \operatorname{int}\{D\}, t \in(0, T],
\end{array}
$$

where

$D \stackrel{\text { def }}{\equiv}\left\{\xi=(x, y, z) \in\left[0, l_{1}\right] \times\left[0, l_{2}\right] \times\left[l_{3}, 0\right], l_{j}>0(j=1,2), l_{3}<0\right\} \quad$ is $n$-layered (in respect to axis OZ) 3D parallelepiped domain; $\quad z \in\left(z_{i-1}, z_{i}\right), i=\overline{1, n} ; \quad z_{0}=l_{3}, z_{n}=0$; $a(\xi) \equiv a_{i}=$ const $>0 \quad$ if $z \in\left(z_{i-1}, z_{i}\right), i=\overline{1, n} ; \quad n$ is the number of layered media parallel to the plane XOY in respect to the vertical axis OZ; $\alpha=\left(\alpha_{1}, \alpha_{2}, \alpha_{3}\right)$, $\alpha_{j}=$ const $(j=\overline{1,3}) ; \quad \beta=$ const $;\langle q, r\rangle$ denotes a scalar product of vectors $q \in \mathbb{R}^{3}$ and $r \in \mathbb{R}^{3}$; a symbol $\nabla_{\eta} Q(\eta, \bullet)$ denotes gradient as to the variable $\eta$ of the scalar function $Q(\eta, \bullet) ; \quad \operatorname{int}\{D\} \quad$ and $\partial D$ correspondingly denote internal and boundary points of the restricted three-dimensional domain $D \subset \mathbb{R}^{3}$; the initial condition

$$
\left.u(\xi, t)\right|_{t=0}=u_{0}(\xi), \xi \in D ;
$$

the boundary conditions

$$
\begin{array}{r}
\left.\gamma_{j, i-1}^{\{i-1\}} \cdot u(\xi, t)\right|_{z=z_{i+j-2}+\varepsilon_{j}}+\left.\gamma_{j, i}^{\{i-1\}} \cdot \frac{\partial u(\xi, t)}{\partial z}\right|_{z=z_{i+j-2}+\varepsilon_{j}} \\
=u_{j, i-1}(x, y, t) ; i=\overline{1,(n+1)}, j=1,2,
\end{array}
$$

where $(x, y, t) \in\left\{D /\left[l_{3}, 0\right]\right\} \times[0, T] ; \quad \varepsilon_{j}=+0 \quad$ if $\quad j=1$, $\varepsilon_{j}=-0 \quad$ if $\quad j=2 ; \quad \gamma_{j, i}^{\{k\}}=\forall$ const $<0 \quad$ if $(j=1) \wedge(i=k=\overline{0, n}), \quad \gamma_{j, i}^{\{k\}}=\forall$ const $>0$ if otherwise;

$$
\begin{gathered}
\left.\theta_{j, i-1}^{\{i-1\}} \cdot u(\xi, t)\right|_{\omega=\omega_{j i}}+\left.\theta_{j, i}^{\{i-1\}} \cdot \frac{\partial u(\xi, t)}{\partial \omega}\right|_{\omega=\omega_{j i}} \\
=\vartheta_{j, i}(\xi / \omega, t) ; i=1,2 ; j=1,2,
\end{gathered}
$$

where $(y, z, t) \in\left\{D /\left[0, l_{1}\right]\right\} \times[0, T]$; $(x, z, t) \in\left\{D /\left[0, l_{2}\right]\right\} \times[0, T] ; \omega=x$ if $i=1, \omega=y$ if $j=2$; $\theta_{j, i}^{\{k\}}=\forall$ const $<0 \quad$ if $\quad(j=1) \wedge(i=k \in\{0 ; 1\})$, $\theta_{j, i}^{\{k\}}=\forall$ const $>0 \quad$ if $\quad$ otherwise; $\left\{\omega_{j i}\right\}_{j=1,2}^{i=1,2}=\left(\begin{array}{cc}0+0 & 0+0 \\ l_{1}-0 & l_{2}-0\end{array}\right) ;$ the consistency conditions

$$
\begin{aligned}
\left.\gamma_{j, i-1}^{\{i-1\}} \cdot u_{0}(\xi, t)\right|_{z=z_{i+j-2}+\varepsilon_{j}}+\left.\gamma_{j, i}^{\{i-1\}} \cdot \frac{\partial u_{0}(\xi, t)}{\partial z}\right|_{z=z_{i+j-2}+\varepsilon_{j}} \\
=\left.u_{j, i-1}(x, y, t)\right|_{t=0+0} ; i=\overline{1,(n+1)}, j=1,2,
\end{aligned}
$$

where $(x, y, t) \in\left\{D /\left[l_{3}, 0\right]\right\} \times[0, T] ; \quad$ the value and meaning of constants $\varepsilon_{j}(i=1,2)$, $\gamma_{j, i}^{\{k\}}(j=1,2 ; i=\overline{0,(n+1)} ; k=\overline{0, n})$ are the same as in case of boundary conditions (3);

$$
\begin{array}{r}
\left.\theta_{j, i-1}^{\{i-1\}} \cdot u_{0}(\xi, t)\right|_{\omega=\omega_{j i}}+\left.\theta_{j, i}^{\{i-1\}} \cdot \frac{\partial u_{0}(\xi, t)}{\partial \omega}\right|_{\omega=\omega_{j i}} \\
=\left.\vartheta_{j, i}(\xi / \omega, t)\right|_{t=0+0} ; i, j=1,2,
\end{array}
$$

where

$$
(y, z, t) \in\left\{D /\left[0, l_{1}\right]\right\} \times[0, T]
$$

$(x, z, t) \in\left\{D /\left[0, l_{2}\right]\right\} \times[0, T]$; the variable $\omega \in\{x, y\}$, and constants $\theta_{j, i}^{\{k\}}(j=1,2 ; i=\overline{0,2} ; k=0,1),\left\{\omega_{j i}\right\}_{j, i \in\{1,2\}}$ have the same values and meaning as for the boundary conditions (4); the conjugating conditions

$$
\left\{\begin{array}{l}
\left.u(\xi, t)\right|_{z=z_{i}+0}=\left.u(\xi, t)\right|_{z=z_{i}-0}, \\
(x, y, t) \in\left\{D /\left[l_{3}, 0\right]\right\} \times[0, T] ; \\
\left.a_{i} \cdot \frac{\partial u(\xi, t)}{\partial z}\right|_{z=z_{i}+0}=\left.a_{i+1} \cdot \frac{\partial u(\xi, t)}{\partial z}\right|_{z=z_{i}-0}, \\
(x, y, t) \in\left\{D /\left[l_{3}, 0\right]\right\} \times[0, T]
\end{array}\right.
$$

for $\forall i=\overline{1,(n-1)}$.

In the formulas (3)-(6) the parameters $\omega$ and $\varepsilon_{i}(i=1,2)$ are introduced only for a compact record of these conditions.

In the mathematical model (1)-(7) the initial data are represented by a piecewise-constant function $a(\xi)$; velocity vector $\alpha$; constant $\beta \in \mathbb{R}^{1}$; constants $l_{i}(i=\overline{1,3}), T>0 ; \quad$ functions $\quad f(\xi, t) \in C\{D \times[0, T]\} ;$ $u_{j, i}(x, y, t) \in C^{1,1,2}\left\{\left\{D /\left[l_{3}, 0\right]\right\} \times[0, T]\right\}(i=\overline{0, n} ; j=1,2) ;$

$\vartheta_{j, 1}(y, z, t) \in C^{1,1,2}\left\{\left\{D /\left[0, l_{1}\right]\right\} \times[0, T]\right\},(j=1,2) ;$

$\vartheta_{j, 2}(y, z, t) \in C^{1,1,2}\left\{\left\{D /\left[0, l_{2}\right]\right\} \times[0, T]\right\},(j=1,2) ; \quad$ constants $\gamma_{j, i}^{\{k\}}(j=1,2 ; i=\overline{0,(n+1)} ; k=\overline{0, n}) ; \quad \theta_{j, i}^{\{k\}}(j=1,2 ; i=\overline{0,2} ; k=0,1)$.

B. Multi-component dynamic model for determination of the main characteristic for the substance circulation process (taking circulation of nitrogen as an example) in the near-surface layers of the natural aquatic environments (natural reservoirs, large basins, lakes and seas)

In this subsection a mathematical model is proposed describing circulation of nitrogen in natural aquatic environments for determination of major characteristics of this process. The constructed model is parametric and is described by a system of partial differential equations. It allows decreasing significantly the uncertainty of parameters of the sophisticated circulation process in the nonhomogeneous media, the example of which is the natural aquatic environment in the presence of powerful sources and sinks. Reducing the uncertainty of parameters is carried out in the way of (a) identification of relationships imposed on the parameters, (b) finding of non-trivial special points of 
the system-model and taking into account the stability preservation conditions in respect to these special points for several structures of the circulation process.

The proposed model is constructed under the following assumptions: the average temperature of the studied natural aquatic environment for the whole period of the circulation process study is assumed to be constant; the total amount of nitrogen in the studied aquatic environment can be represented in the form of organic and inorganic nitrogen, where the organic nitrogen in its turn can be represented also in two forms - as animated and unanimated nitrogen; the reserve of nitrogen in the studied aquatic environment is replenished (a) by means of molecular nitrogen adoption of the air by some free nitrogen fixing agents and (b) by some types of seaweed; processes of nitrogen fixing by phytoplankton and bacterial plankton have linear interdependence (with a known coefficient of linearity); mineral nitrogen in the aquatic environment is used only by some types of seaweed and planktons; protein substances of plants and animal species formed in the studied aquatic environment, after dying off of the organisms are subjected to mineralization with the assistance of bacteria, moreover, decomposition of such protein substances evolves nitrogen, generally in the form of ammonia; in the studied process of circulation there occurs direct denitrification (denitrification is a decomposition of nitrogenous compounds with generation of free nitrogen) as well as circumstantial denitrification (circumstantial denitrification - this is a chemical effect of $\mathrm{NO}_{2}^{-}$, ammonium salts and amino acids with generation of free nitrogen); the studied circulation process also includes deammonification (decomposition by microorganisms of nitrogencontaining organic compounds with generation of free nitrogen).

So, the offered parametric model anticipates determination of the vector $u \stackrel{\text { def }}{\equiv}\left(u_{\text {ph.pl. }}, u_{\text {bac.pl. }}, u_{\text {zoo.pl. }}, u_{\text {inor. nit. }}, u_{\text {or.nit. }}\right)(\xi, t) \in C^{0,1}\{D \bigcup[0, T]\}$ of dynamic variables/functions $u_{\text {ph.pl. }}(\xi, t), u_{\text {bac.pl. }}(\xi, t)$, $u_{z o o . p l .}(\xi, t), \quad u_{\text {inor.nit. }}(\xi, t)$ and $u_{\text {or.nit. }}(\xi, t)$, where $D \stackrel{\text { def }}{\equiv}\left\{\xi=\left(x_{1}, x_{2}, x_{3}\right): l_{x_{3}} \leq x_{3} \leq 0 ; 0 \leq x_{i} \leq l_{x_{i}}(i=1,2)\right\}$, from the non-linear system

$$
\begin{aligned}
& \int \frac{1}{u_{p h . p l .}(\xi, t)} \cdot \frac{\partial u_{\text {ph.pl. }}(\xi, t)}{\partial t}=k_{1}(\xi)+k_{2}(\xi) \cdot u_{o r . n i t .}(\xi, t) \\
& +k_{3}(\xi) \cdot u_{\text {inor.nit. }}(\xi, t)-k_{4}(\xi) \cdot u_{z o o p . p l .}(\xi, t)-k_{5}(\xi)-u_{\text {flowing }}(t), \\
& (\xi, t) \in \operatorname{int}\{D\} \cup(0, T], \operatorname{int}\{D\} \stackrel{\text { def }}{\equiv} D / \partial D, \\
& \frac{1}{u_{\text {bac.p. }}(\xi, t)} \cdot \frac{u_{\text {bac.p. }}(\xi, t)}{\partial t}=k_{6}(\xi)-k_{7}(\xi)-k_{8}(\xi)-k_{9}(\xi) \\
& -u_{\text {flowing }}(t)+k_{10}(\xi) \cdot u_{\text {or.nit. }}(\xi, t)-k_{11}(\xi) \cdot u_{\text {inor.nit. }}(\xi, t) \\
& -k_{12}(\xi) \cdot u_{z o o p p l .}(\xi, t),(\xi, t) \in \operatorname{int}\{D\} \cup(0, T] \text {, } \\
& \frac{1}{u_{z o o . p l .}(\xi, t)} \cdot \frac{u_{z o o p . p l}(\xi, t)}{\partial t}=k_{4}(\xi) \cdot u_{p h . p l .}(\xi, t)+k_{12}(\xi) \cdot u_{p h . p l .}(\xi, t) \\
& +k_{13}(\xi) \cdot u_{\text {or:nit. }}(\xi, t)-k_{14}(\xi)-k_{15}(\xi)-k_{16}(\xi) \cdot u_{\text {flowing }}(t), \\
& \{(\xi, t) \in \operatorname{int}\{D\} \cup(0, T] \text {, } \\
& \frac{1}{u_{\text {inor.nit. }}(\xi, t)} \cdot \frac{u_{\text {inor.nit. }}(\xi, t)}{\partial t}=\frac{c_{1}(\xi)+c_{2}(\xi)}{u_{\text {inor.nit. }}(\xi, t)}+k_{14}(\xi) \cdot \frac{u_{\text {zoo.pl. }}(t)}{u_{\text {inor.n.nit. }}(\xi, t)} \\
& +k_{8}(\xi) \cdot \frac{u_{\text {bac.pl. }}(t)}{u_{\text {inor. rit. }}(\xi, t)}-k_{11}(\xi) \cdot u_{\text {bac.pl. }}(\xi, t)-k_{3}(\xi) \cdot u_{\text {ph.pl. }}(\xi, t) \\
& -u_{\text {flowing }}(t),(\xi, t) \in \operatorname{int}\{D\} \cup(0, T] \text {, } \\
& \frac{1}{u_{\text {or.nit. }}(\xi, t)} \cdot \frac{u_{\text {or.nit. }}(\xi, t)}{\partial t}=\frac{c_{3}(\xi)+c_{4}(\xi)}{u_{\text {or.nit. }}(\xi, t)}+k_{5}(\xi) \cdot \frac{u_{\text {ph.pl. }}(\xi, t)}{u_{\text {or.nit. }}(\xi, t)} \\
& +k_{7}(\xi) \cdot \frac{u_{\text {bac.pl. }}(\xi, t)}{u_{\text {or.nit. }}(\xi, t)}+k_{15}(\xi) \cdot \frac{u_{\text {zoo.pl. }}(\xi, t)}{u_{\text {or.nit. }}(\xi, t)}-k_{10}(\xi) \cdot u_{\text {bac.pl. }}(\xi, t) \\
& -k_{2}(\xi) \cdot u_{p h . p l .}(\xi, t)-k_{13}(\xi) \cdot u_{z o o . p l .}(\xi, t)-k_{17}(\xi)-u_{\text {flowing }}(t) \text {, } \\
& (\xi, t) \in \operatorname{int}\{D\} \cup(0, T] \text {, }
\end{aligned}
$$

with initial conditions

$$
\left\{\begin{array}{l}
\left.u_{\text {ph.pl. }}(t)\right|_{t=0}=u_{\text {ph.pl. }}^{0}(\xi) ;\left.u_{\text {bac.pl. }}(t)\right|_{t=0}=u_{\text {bac.pl. }}^{0}(\xi) ; \\
\left.u_{z o o \text {.pl. }}(t)\right|_{t=0}=u_{z o o p . p l .}^{0}(\xi), \quad \xi \in D, \\
\left.u_{\text {inor.nit. }}(t)\right|_{t=0}=u_{\text {inor.nit. }}^{0}(\xi) ;\left.u_{\text {or.nit. }}(t)\right|_{t=0}=u_{\text {or.nit. }}^{0}(\xi), \xi \in D,
\end{array}\right.
$$

where functions $u_{\text {ph.pl. }}(\xi, t), \quad u_{\text {bac.pl. }}(\xi, t), \quad u_{z o o . p l}(\xi, t)$, $u_{\text {inor.nit. }}(\xi, t)$ and $u_{\text {or.nit. }}(\xi, t)$ denote respectfully the desired amount of phytoplankton, bacterial plankton, zooplankton, inorganic nitrogen and organic nitrogen at the time moment $t \in[0, T]$ at the point $\xi \in D ; T$ is the given finite moment of time, during which the process of substance circulation in the near-surface layers of natural aquatic environments is studied; $l_{x_{i}}(i=\overline{1,3}): l_{x_{1}}>0, l_{x_{2}}>0, l_{x_{3}}<0$ are the known boundaries of the considered "parallelepiped" domain of natural aquatic environments; the initial functions $u_{\text {ph.pl. }}^{0}(\xi), u_{\text {bac.pl. }}^{0}(\xi), u_{\text {zoo.pl. }}^{0}(\xi), u_{\text {inor.nit. }}^{0}(\xi), u_{\text {or.nit. }}^{0}(\xi), \xi \in D$ are a priori known functions, which are continuous in the closed domain $D$; the functions $k_{i}(\xi)(i=\overline{1,17}), \quad \xi \in \operatorname{int}\{D\}, \quad c_{i}(\xi)(i=\overline{1,4}), \xi \in \operatorname{int}\{D\}$ and $u_{\text {flowing }}(t), t \in(0, T]$ have the following meaning: $k_{1}(\xi)$ is a coefficient of nitrification of phytoplankton; $k_{2}(\xi)$ is a coefficient of organic nitrogen absorption by phytoplankton; $k_{3}(\xi)$ is a coefficient of mineral nitrogen absorption by phytoplankton; $k_{4}(\xi)$ is a 
coefficient of phytoplankton consumption by zooplankton; $k_{5}(\xi)$ is a coefficient of emission of organic nitrogen by phytoplankton; $k_{6}(\xi)$ is a coefficient of nitrification of bacterial plankton; $k_{7}(\xi)$ is a coefficient of emission of organic nitrogen by bacterial plankton; $k_{8}(\xi)$ is a coefficient of emission of mineral nitrogen by bacterial plankton; $k_{9}(\xi)$ is a coefficient of denitrification: denitrification - is decomposition of nitrogenous compounds with free nitrogen generation; $k_{10}(\xi)$ is a coefficient of organic nitrogen processing by bacteria; $k_{11}(\xi)$ is a coefficient of mineral nitrogen processing by bacteria; $k_{12}(\xi)$ is a coefficient of bacterial plankton consumption by zooplankton; $k_{13}(\xi)$ is a coefficient of organic nitrogen consumption by zooplankton; $k_{14}(\xi)$ is a coefficient of mineral nitrogen emission by zooplankton; $k_{15}(\xi)$ is a coefficient of organic nitrogen emission by zooplankton; $k_{16}(\xi)$ is a coefficient of zooplankton discharge by higher level predaceous organisms; $k_{17}(\xi)$ is a coefficient of organic nitrogen supply to the lower layer of the considered domain $D$ of natural aquatic environments - the domain of near-surface layers of natural aquatic environments; $c_{1}(t)$ is the inflow of inorganic nitrogen that is equal to the sum of (a) main feeding river sinks, (b) rain surface sinks, (c) inner drainage of mineral fertilizers into the soil, (d) industrial and household discharges, (e) atmospheric precipitations on the water area: water area - is a region of water surface within the set boundaries; $c_{2}(t)$ is the inflow of mineral nitrogen from lower layer silt; $c_{3}(t)$ is the inflow of organic nitrogen from lower layer silt; $c_{4}(t)$ is the inflow of organic nitrogen, equal to the sum of (a) main feeding river flows, (b) atmospheric precipitations on the water area, (c) decaying biomass of phytoplankton and higher level of marine vegetation, (d) emissions of living phytoplankton; $u_{\text {flowing }}(t)$ the power of flow (water circulation; evaporation; etc.).

Remark 1. In the model (8), (9) modeling units are tons of nitrogen per time unit (for instance, per year).

Remark 2. Model (8), (9) having any fixed value of spatial variable $\xi=\xi_{\text {fix }} \in D$ becomes a Cauchy problem for the system of ordinary non-linear differential equations, and in this case it is an adequate model for determination of nitrogen circulation in large basins, reservoirs, lakes, ponds, etc.

Remark 3. In the proposed model (8), (9) to describe the functional significance of the coefficient $k_{9}(\xi)$, which denoted coefficient of denitrification, it was discussed that the denitrification is a decomposition of nitrogenous compounds with generation of free nitrogen. This definition requires a more precise specification. The transition of nitrogen into the gaseous form of nitrates $\left(\mathrm{NO}_{3}^{-} \rightarrow \mathrm{NO}_{2}^{-} \rightarrow \mathrm{N}_{2}\right)$

is called denitrification. Generally speaking, this process in the presence of denitrifying bacteria occurs fairly rapidly only when there are nitrates present, the amount of easily assimilable organic substance is sufficient, as well as anaerobic conditions fulfilled. If the medium together with $\mathrm{NO}_{2}^{-}$contains ammonium salts (or amino acids), the free nitrogen can be generated due to their chemical interaction, namely, $2 \mathrm{KNO}_{2}+\left(\mathrm{NH}_{4}\right) \mathrm{SO}_{4} \rightarrow 2 \mathrm{NH}_{4} \mathrm{NO}_{2}+\mathrm{K}_{2} \mathrm{SO}_{4} ; \quad \mathrm{NH}_{4} \mathrm{NO}_{2} \rightarrow \mathrm{N}_{2}+$ $2 \mathrm{H}_{2} \mathrm{O}$. This process is called (see, for instance, [20]) circumstantial denitrification. Nitrogen losses are also possible in the result of deammonification $\left(\mathrm{NH}_{4} \rightarrow \mathrm{N}_{2}\right)$, and also when generating fugitive nitrogen oxides with the participation of certain amino acids and a variety of unstable nitrogen containing compounds ([11]).

As it was mentioned at the beginning of this subsection, in the mathematical model (8), (9) we supposed that all the above mentioned processes occur to a greater or lesser degree, however, in [21], it is shown that the most frequently denitrification is observed in soil, and not in the layers of water.

In the model (8), (9) for its simplification all the above mentioned processes are joined into one process called denitrification with one functional coefficient $k_{9}(\xi)$, covering the other possible processes associated with the loss of nitrogen in natural aquatic environments.

\section{Model for determination of oxygen condition sensitivity for the Baltic Sea}

In this subsection a mathematical model for determination sensitivity of the oxygen condition in the Baltic Sea is proposed. As it is shown in the work [5], the models sensitivity study anticipates identifying of special features of ecosystem dynamics within the domains bounded by the bifurcation surfaces.

Methods of the sensitivity theory can be used to solve the two types of problems that arise when constructing dynamic multi-component models, including simulation models: (a) at the stage of establishment of the model structure and for binding parameters of the models, which provide concordance during some observations time period; (b) at the stage of studying the model with already established structure for finding irregular special points (that is, "weak places") and stationary points (that is, anaerobic places) of the aquatic ecosystem, as well as for determination of critical values of parameters when modelling toxic effect and anthropogenic eutrophication (eutrophication - is the process of total productivity growth of the water reservoir ecosystem, 
which includes water masses, bottom deposits and microorganisms living there; eutrophication - is the increase of the level of water primary production owing to the increase in the concentration of biogenic elements there, that is mainly nitrogen and phosphorus).

The model proposed below allows determination of peculiarities of oxygen state dynamics, which cannot be determined by simple enumeration of parameters and/or when using purely statistical methods of parameters estimation.

Moreover, the proposed model allows determining the qualitative properties of the oxygen state dynamics, which significantly reduces the uncertainty in sophisticated interrelations between parameters of dynamics and the environment, allows making adequate high precision forecasts in respect to anthropogenic impact onto the ecosystem and, therefore, reveals trends in the ecosystem state of the sea. Finally, the proposed model can be used as a primary model to determine the condition that leads to anaerobic zones growth strengthening in the Baltic Sea.

As a major restriction of the proposed model there can be noted the impossibility of its usage for the study of the seasonal Baltic Sea ecosystem dynamics in the conditions of aerobic and anaerobic states being below the halocline level.

Remark 4. This model is essentially based on the results of works [7], [12] taking into account the modifying changes from works [22]-[25], namely, in the Sjoberg anaerobic model non-autonomous system of ordinary differential equations, where in the direct form there are present functions of vertical turbulent mixing, function of lighting and function of temperature, is substituted by autonomous system of equations (such substitution is approved by Floquet and Lyapunov's theorem: the information on the theory of Floquet and Lyapunov, namely, the importance and benefits of Floquet-Lyapunov theorem can be found in book [26] and fundamental monograph [27]; but the widest applications of Floquet-Lyapunov theorem are given in the book [28]).

It is required to determine a vector $u(\xi, t) \stackrel{\text { def }}{\equiv}\left(\bar{u}_{\text {inor.phosph. }}, \underline{u}_{\text {inor.phosph. }}, \bar{u}_{\text {or.phosph. }}, \underline{u}_{\text {or.phosph. }}, \bar{u}_{\text {ph.pl. }}, \underline{u}_{\text {oxyg. }}\right)(t)$ of dynamic variables/functions $\bar{u}_{\text {inor:phosph. }}(t)$, $\underline{u}_{\text {inor.phosph. }}(t), \bar{u}_{\text {or.phosph. }}(t), \underline{u}_{\text {or.phosph. }}(t), \bar{u}_{\text {ph.pl. }}(t)$ and $\underline{u}_{\text {oxyg. }}(t)$ from the system of ordinary non-linear differential equations

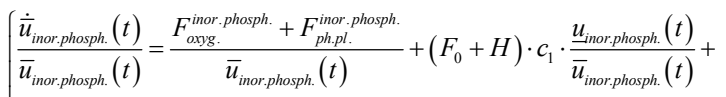

$$
\begin{aligned}
& +k_{1} \cdot T^{\circ} \cdot \frac{\bar{u}_{\text {or } p \text { hosph. }}(t)}{\bar{u}_{\text {inor } \text {.phosph. }}(t)}-\left(H+F_{\text {oxyg. }}+F_{0}\right) \cdot c_{2}-k_{2}-k_{3} \cdot I \cdot T^{\circ} \cdot \bar{u}_{\text {ph.pl. }}(t) \text {, }
\end{aligned}
$$

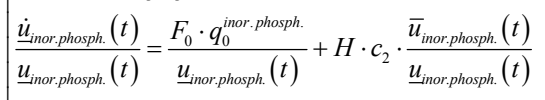

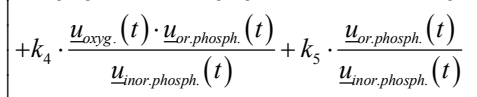

$$
\begin{aligned}
& -\left(F_{0}+H\right) \cdot c_{1}-k_{6} \cdot \underline{u}_{\text {oxyg. }}(t) \text {, } \\
& \frac{\dot{\bar{u}}_{\text {or.phosph. }}(t)}{\bar{u}_{\text {or.phosph. }}(t)}=\left(F_{0}+H\right) \cdot c_{1} \cdot \frac{u_{\text {or.phosph. }}(t)}{\bar{u}_{\text {or.phosph. }}(t)}+k_{7} \cdot \frac{\bar{u}_{\text {ph.pl. }}(t)}{\bar{u}_{\text {or.phosph. }}(t)} \\
& \left\{-\left(H+F_{\text {oxyg. }}+F_{0}\right) \cdot c_{2}-k_{8}-k_{9}-k_{1} \cdot T^{\circ},\right.
\end{aligned}
$$

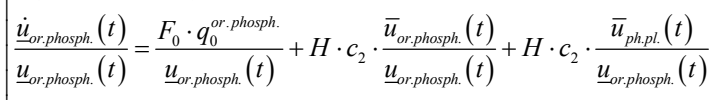

$$
\begin{aligned}
& +k_{9} \cdot \frac{\bar{u}_{\text {or phosph. }}(t)}{\underline{u}_{\text {or phosph. }}(t)}-\left(F_{0}+H\right) \cdot c_{1}-k_{10}-k_{5}-k_{4} \cdot \underline{u}_{\text {oxyg. }}(t) \text {, } \\
& \frac{\dot{\bar{u}}_{\text {ph.pl. }}(t)}{\bar{u}_{\text {ph.pl. }}(t)}=k_{3} \cdot I \cdot T^{\circ} \cdot \bar{u}_{\text {inor phosph. }}(t)-\left(H+F_{0}+F_{\text {oxyg. }}\right) \cdot c_{2}-k_{7} \text {, } \\
& \left\{\begin{array}{l}
\frac{\underline{\underline{u}}_{\text {oxyg. }}(t)}{\underline{u}_{\text {oxyg. }}(t)}=\frac{F_{0} \cdot q_{0}^{\text {oxyg. }}}{\underline{u}_{\text {oxyg. }}(t)}+\frac{H \cdot q_{1}^{\text {oxyg. }}}{\underline{u}_{\text {oxyg. }}(t)}-\left(F_{0}+H\right) \cdot c_{1}-\frac{k_{11}}{\underline{u}_{\text {oxyg. }}(t)} \\
-k_{12} \cdot k_{4} \cdot \underline{u}_{o r \text {. phosph. }}(t)-k_{5} \cdot \frac{u_{o r . p h o s p h .}(t)}{\underline{u}_{\text {oxyg. }}(t)}
\end{array}\right.
\end{aligned}
$$

and initial conditions

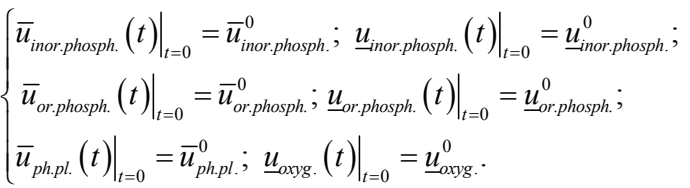

In the model (10), (11) such designations and assumptions take place: the range of definition for each equation forming the system (10) is determined by the semi interval $(0, T]$; functions $\bar{u}_{\text {inor.phosph. }}(t)$, $\underline{u}_{\text {inor.phosph. }}(t), \bar{u}_{\text {or.phosph. }}(t), \underline{u}_{\text {or.phosph. }}(t), \bar{u}_{\text {ph.pl. }}(t)$ and $\underline{u}_{\text {oxyg. }}(t)$ denote accordingly the desired amount of inorganic phosphorus above the layer of Baltic Sea, where the salinity gradient is maximal (i.e. above the layer, where sea water salinity maximally changes - such layer is called halocline: halocline is a vertical zone in the oceanic water column in which salinity changes rapidly with depth, located below the well-mixed: for instance,

see http://www.britannica.com/EBchecked/topic/252980/h alocline), inorganic phosphorus below the halocline, organic phosphorus above the halocline, organic phosphorus below the halocline, phytoplankton above the halocline and oxygen below the halocline at the moment of time $t \in[0, T]: T$ is the given time period, during which the dynamics of oxygen condition of the Baltic Sea is studied; constants $\bar{u}_{i n o r: p h o s p h .}^{0}, \underline{u}_{i n o r . p h o s p h .}^{0}$, $\bar{u}_{o r \text {.phosph. }}^{0}, \underline{u}_{o r \text {.phosph. }}^{0}, \bar{u}_{p h . p l .}^{0}$ and $\underline{u}_{\text {oxyg. }}^{0}$ from the initial conditions (11) are supposed to be known priory; values of constants (let's call them inner model 
constants) $I, T^{\circ}, H$ and parameters values (let's call them inner parameters of the model) $k_{i}(i=\overline{1,12})$, $c_{i}(i=1 ; 2), \quad F_{0}, F_{\text {oxyg. }}^{\text {inor.phosph. }}, F_{\text {ph.pl. }}^{\text {inor phosph. }}, F_{\text {oxyg. }}, q_{0}^{\text {inor.phosph. }}$, $q_{0}^{\text {or.phosph. }}, \quad q_{0}^{\text {oxyg. }}, \quad q_{1}^{\text {oxyg. }}$ of the differential equation system (10) are given below in accordance with research results [12]: $I=8$ hours; $T^{\circ}=8{ }^{\circ} \mathrm{C} ; H=2.125$ $\mathrm{km} /\left(\right.$ twenty-four hours); $k_{1}=0.0041 /{ }^{\circ} \mathrm{C}$ per twentyfour hours; $k_{2}=0.00006931 /$ (twenty-four hours); $k_{3}=0.000000041 / \mathrm{t}$ Phosph. hour ${ }^{\circ} \mathrm{C} \cdot$ (twenty-four hours); $k_{4}=0.000537 \quad 1 / \mathrm{km}^{3} \quad \mathrm{O}_{2}$.(twenty-four hours); $k_{5}=0.001558 ; \quad k_{6}=0.00000217 \quad 1 / \mathrm{km}^{3} \quad \mathrm{O}_{2} \cdot$ (twenty-four hours); $\quad k_{7}=0.065 \quad 1 /$ (twenty-four hours); $k_{8}=0.000018461 /$ (twenty-four hours); $k_{9}=0.00022$ $1 /$ (twenty-four hours); $k_{10}=0.00022 \quad 1 /$ (twenty-four hours); $k_{11}=0.00042061 / \mathrm{km}^{3} \mathrm{O}_{2} \cdot$ (twenty-four hours); $k_{12}=0.000199 \quad 1 / \mathrm{km}^{3} \quad \mathrm{O}_{2} \cdot($ twenty-four hours); $c_{1}=0.000027651 / \mathrm{km}^{3} ; c_{2}=0.00010531 / \mathrm{km}^{3} ; F_{0}=1.308$ $\mathrm{km}^{3} /$ (twenty-four hours); $F_{\text {oxyg. }}^{\text {inor. phosph. }}+F_{\text {ph.pl. }}^{\text {inos. }}$. Phosph./ (twenty-four hours); $\quad F_{\text {oxyg. }}=1.308$ $\mathrm{km}^{3} /$ (twenty-four hours); $\quad q_{0}^{\text {inor.phosph. }}=0.001 \quad \mathrm{~km}^{3}$ Phosph. $/ \mathrm{km}^{3} ; \quad q_{0}^{\text {or.phosph. }}=0.003 \quad \mathrm{~km}^{3} \quad$ Phosph. $/ \mathrm{km}^{3}$; $q_{0}^{\text {oxy. }}=0.01 \mathrm{~km}^{3} \mathrm{O}_{2} / \mathrm{km}^{3} ; q_{1}^{\text {oxy. }}=0.01 \mathrm{~km}^{3} \mathrm{O}_{2} / \mathrm{km}^{3}$.

Remark 5. Due to the fact that almost 30 years have passed from the moment of publishing the work [12] and in this period significant geopolitical changes occurred in Europe, in particular, in the Baltic Sea Countries (breakdown of the USSR; acquisition of sovereignty of three Baltic states; decrease of industrial power of some of the Baltic Sea Countries (Latvia, Lithuania, Estonia, Poland, Russia) and, as consequence, change of anthropogenic impact on the Baltic Sea by those countries; increase of industrialization of developed Baltic Sea Countries Germany, Sweden, Finland, Denmark and other factors), it is evident that the values of model (10), (11) inner constants and parameters, which were calculated in the work [12] and borrowed by us without any changes, obviously have to be specified more precisely. As it could be seen from the offered model (10)-(11), the corresponding changes/specifications of such inner constants and parameters of the model do not change the essence of the proposed model, except the coordinates of positive stationary points (one of the positive stationary points, within the small vicinity of which the model is stable will be the desired condition of the Baltic Sea!) of the system (10) will change: in [7], [12] the Sjoberg model had two positive stationary points, one of them was stable and, therefore, it described the real condition of oxygen in the Baltic Sea in the 70's of the XX-th century.

Remark 6. In the model (10), (11) units of modelling - tons of phosphorus ( $t$ Phosph.) per twenty-four hours and cubic kilometer of oxygen (km3), namely, measuring units of functions $\bar{u}_{\text {inor.phosph. }}(t), \quad \underline{u}_{\text {inor.phosph. }}(t), \quad \bar{u}_{\text {or.phosph. }}(t), \quad \underline{u}_{\text {or.phosph. }}(t)$, $\bar{u}_{\text {ph.pl. }}(t)$ are $\mathrm{t}$ Phosph/(twenty-four hours), but measuring units of function $\underline{u}_{\text {oxyg. }}^{0}$ are $\mathrm{km}^{3} \mathrm{O}_{2}$.

\section{CONCLUSIONS}

In the present paper there is proposed a complex of continuous qualitative models having dynamic parameters for analysis, evaluation and forecast of aquatic (water reservoirs, lakes and the Baltic Sea) ecosystem status in Latvia. All the constructed models are described in terms of differential equations and mathematical physics and are considered to be evolutional models. Below it is given a short description of the models proposed. The first model is aimed at discovering the pollutant concentration dynamics in the Baltic Sea. This model can be used as the primary model for the better monitoring of the Baltic Sea. The second model is designed to determine the basic characteristics of nitrogen circulation in the natural aquatic environments. This model allows to reduce substantially (in comparison with the other models constructed to this date and known to the authors of this paper) the uncertainty in the parameters of the sophisticated process of circulation in the inhomogenous media, which is typical for natural aquatic environment with powerful sources and sinks. Let us note that it is possible to consider minimizing the number of uncertain model parameters issue by (a) identifying relationships imposed on the parameters, (b) finding non-trivial special points of the systemmodel, and taking into account those points found in a consequent way for the several structures of the circulation processes following the conditions of stability maintenance. In further studies authors plan to carry out the abovementioned minimization for the uncertain model parameters number. The third is a mathematical model that allows to determine the sensitivity of oxygen condition in the Baltic Sea. This model provides a possibility to (a) identify those features of oxygen condition dynamics, which are not revealed during the regular enumeration and/or using pure statistical methods of parameters evaluation; (b) to identify qualitative properties of the oxygen condition dynamics, which reduces significantly the uncertainty in the complex interrelations between dynamics parameters and the environment, making it possible to forecast the anthropogenic impact on the ecosystem with a high degree of accuracy, and, therefore, to identify existing trends in the ecosystem of the sea. However, it should be noted that this model cannot be used for the study of the seasonal Baltic Sea ecosystem dynamics in the conditions of aerobic and anaerobic states being below the halocline level, and this is regarded to be a limitation of the model. For this reason, third model can be used only as a primary 
model for identification of condition that leads to anaerobic zones growth strengthening in the Baltic Sea.

To conclude with, let us note that authors of this paper are intended to continue the further investigation taking the benefit of both qualitative and quantitative studies for all three models as well as to develop the stable analytical and numerical methods for their solution ensuring the corresponding computer-based implementation.

\section{ACKNOWLEDGMENTS}

The present article was executed within the framework of the following two Research Projects: 1) The State Research Programme "NextIT": Next generation Information and Communication Technologies (for both authors); 2) The European Regional Development Fund Project No. 2014 / 0029 / 2DP / 2.1.1.1 / 14 / APIA / VIAA / 088: "Development of an experimental long flight distance unmanned aerial vehicle prototype for multi-purpose environmental monitoring" (for the first author).

\section{$\mathrm{V}$ REFERENCES}

[1] G. I. Marchuk, Mathematical modelling in environmental problem. Moscow: Science, 1982.

[2] J. Jennifers, Introduction to system analysis: application for ecology. Moscow: World, 1981.

[3] Yu. P. Zaitsev, and G. G. Polikarpov, "Ecological processes in the critical areas of the Black Sea: synthesis of the results of two research dimensions from the middle of the XX to the beginning of XXI centuries." Marine Ecological Journal, Vol. 1, Issue 1, pp. 33-55. 2002.

[4] J. Hofbauer, and K. Sigmund, The theory of Evolution and dynamical systems. London: Cambridge University Press, 1988.

[5] L. M. Nedostup, "Sensitivity of the water ecosystem models that are affected by the anthropogenic factor." in Natural waters preservation, protection and quality improvement problems. Moscow: Science, 1982, pp. 139-155.

[6] B. Bolin, "Model studies of the Baltic Sea." University of Stockholm, Institute of Meteorology, Ambio Special Report (Report GH-4), No. 1, 1972. pp. 115-119.

[7] S. Sjoberg, "A mathematical and conceptual framework for models of the pelagic ecosystems of the Baltic Sea." University of Stockholm, Asko Laboratory, Report No. 1, 1980. 206 p.

[8] Yu. M. Barabasheva, L. I. Brodsky, and G. I. Devyatkova, "About evaluation of parameters in the point model of aquatic ecosystem: Theoretical ecology." Moscow: Lomonosov Moscow State University publishing, 1987, pp. 105-110.

[9] Sh. E.Guseynov, E. A. Kopytov, and O. V. Schiptsov, Mathematical Models of an exhaust concentration dynamics in urban atmosphere. Riga: Transport and Telecommunication Institute Press, 2010.

[10] J. S.Rimshans, I. N. Esau, S. S. Zilitenkevich, and Sh. E. Guseynov, "Analytical-Numerical Solution for the One Dimensional PBL Turbulence Model." Proceedings of the 18th Symposium on Boundary Layers and Turbulence under the aegis of the American Meteorological Society, Stockholm, Sweden June 09-13, 2008. http://ams.confex.com/ ams/pdfpapers/139877.pdf.

[11] Yu. N. Sergeyev, "Problem of mathematical modeling of multicomponent physico-biological marine system." Herald of the Leningrad State University, Issue: 24, pp. 114-125, 1972.

[12] S. Sjoberg, F. Wulff and P. Wahllstrom, "Computer Simulations of Hydrochemical and Biological processes in the Baltic." University of Stockholm, Asko Laboratory, Report No 1, 1972. $180 \mathrm{p}$

[13] L. F. Serdiutskaya, "Study of mathematical models of environmental systems using multivariate factor analysis." International Journal on Engineering Simulation, Vol. 17, pp. 417-428, 2000

[14] L. F. Serdyutskaya, "About some aspects of factorial analysis application for the problems of environmental simulation." in Modelling and diagnostics of the sophisticated processes and systems, Kiev: Scientific thaught, 1997, pp. 35-40.

[15] V. I. Belyaev, Ye. D. Korenyuk, and V. K. Hrusch, Computer modelling of the subsurface water circulation and pollution dynamics. Dnepropetrovsk: Science and Education, 2001.

[16] The Environmental Performance Index 2014. Yale Center for Environmental Law \& Policy, Yale University 2015. [Online]. Available: http://epi.yale.edu/epi/country-profile/latvia [Accessed: May 10, 2015].

[17] HELCOM Initial Holistic Assessment. Ecosystem Health of the Baltic Sea in 2003-2007. Baltic Sea Environment Proceedings, No. 122, 2008, 66 p.

[18] Latvian Ministry of Environment. Environmental Policy Strategy in 2009-2015. Informative section. Riga, 2009, 53 p.

[19] Sh. E.Guseynov, J. S. Rimshans, and E. A. Kopytov, "Solution of the Model of Exhaust Concentration Dynamics in Urban Atmosphere under Unknown Turbulent Air Flow Velocity." International Journal of Procedia Environmental Sciences, Series: Urban Environmental Pollution, 2011, No 4, pp. 35-42, 2011.

[20] S. I. Kuznetsov, Micro flora of the lakes and its geochemical activity. Moscow: Science, 1970.

[21] W. Eppley, E. U. Renger, and E. L. Uenrick, "A study of plankton dynamics and nutrient cycling in the central gyre of the North Pacific Ocean." Journal on Limnology and Oceanography, Vol. 18, Issue 4, pp. 534-555, 1973.

[22] Baltic Marine Environment Protection Commission: Helsinki Commission. Baltic Sea Environment Proceedings, No. 16, $1986,176 \mathrm{p}$.

[23] Baltic Marine Environment Protection Commission: Helsinki Commission. First Periodic assessment of the State of the Marine Environment of the Baltic Sea area, General Conclusions. Baltic Sea Environment Proceedings, No. 17A, $1986,56 \mathrm{p}$.

[24] V. B. Georgievsky, "Identification and verification of the water ecosystem models." in Natural waters preservation, protection and quality improvement problems. Moscow: Science, 1982, pp. 156-163.

[25] V. B. Georgievsky, "Identification and mathematical modeling of the eutrophication processes of the sea ecosystems." Ambio Special Report, Vol. 5, pp. 165-176, 1983.

[26] J.Hofbauer, and K. Sigmund, The theory of Evolution and dynamical systems. London: Cambridge University Press, 1988.

[27] V. I. Arnold, Additional chapters of the ordinary differential equations theory. Moscow: Science, 1978.

V. A. Yakubovich, and V. M. Starshinsky, Linear differential equations with periodic coefficients and their applications. Moscow: Science, 1972. 